Forthcoming in Streit um die Freiheit: Philosophische und theologische Beiträge, ed. Wendel, von Stosch, Langenfeld, and Breul

\title{
Free Will and Abilities to Act
}

\author{
Randolph Clarke
}

We have abilities to act, abilities to do things such as make decisions, move about, and collaborate with others in various ways. We exercise these abilities on various occasions. And on various occasions we have abilities to act that we don't exercise; we have unexercised abilities.

So it seems. Some theorists say that (at least) the last of these claims is true only if our world is indeterministic in some specific way. ${ }^{1}$ Determinism, they say, is incompatible with agents' having abilities to do anything other than what they actually do. With free will taken to require such abilities to do otherwise, it is then said that the truth of determinism would preclude our having free will.

Employing a sophisticated account of abilities to act, Kadri Vihvelin (2013) has recently offered a rebuttal of this position. Her response advances each of the following claims: (i) abilities of an important kind are "structurally" like dispositions such as fragility; (ii) ascriptions of dispositions can be analyzed in terms of counterfactual conditionals; (iii) ascriptions of abilities of the kind in question can be analyzed similarly; and (iv) we have the free will we think we have by having abilities of this kind and being in circumstances that are propitious for their exercise.

Here I offer a close examination of Vihvelin's view of abilities to act and their relation to free will. I'll raise doubts about each of the numbered claims. Further, I'll argue, even if abilities of the kind in question are dispositions, and even if determinism is compatible with our

\footnotetext{
${ }^{1}$ I say “at least," because some theorists claim that determinism would preclude agency altogether, and thus preclude the existence even of exercised abilities to act. For a recent argument to this effect, see Steward (2012).
} 
commonly having unexercised abilities of this kind, the compatibility of determinism and free will remains in question.

\section{Kinds of Ability}

Writers on abilities to act draw a variety of distinctions between various kinds of ability: hypothetical and categorical, ${ }^{2}$ general and specific, ${ }^{3}$ and simple and intentional, ${ }^{4}$ to mention just a few. The main distinction that Vihvelin draws is between what she calls narrow and wide abilities.

A narrow ability to $A$, where $A$-ing is some type of action, is, as Vihvelin puts it, "what it takes” to A (2013: 11). What it takes to A, she holds, includes whatever skills, competence, or know-how are required to $A$-and to do it without too much luck. ${ }^{5}$ Further, Vihvelin says, a narrow ability includes "the psychological and physical capacity” to exercise the required skills, competence, or know-how. Even if one knows how to play guitar, one lacks a narrow ability to do so if one is soundly sleeping or fully paralyzed; and pathological fears or broken bones can preclude having narrow abilities to do certain things.

Having a wide ability to $A$ is having a narrow ability to $\mathrm{A}$ and being in circumstances that are, as we might put it, friendly to the exercise of that ability. One must have the means and the

\footnotetext{
${ }^{2}$ Campbell (2011: 86-87).

${ }^{3}$ See, e.g., Maier (2014) and Mele (2006: 18). Berofsky (2011: 155) draws a similar-though not exactly the same- distinction between what he calls a type ability and a token power. Fischer distinguishes general abilities from "the sort of ability that corresponds to J. L. Austin's 'all-in' sense of 'can'” or 'can in the particular circumstances”” (2011: 262). (See Austin [1979: 229].)

${ }^{4}$ Mele (2006: 18-19).

${ }^{5}$ Having the requisite skill, competence, or know-how suffices, Vihvelin says, for having what is commonly called a general ability. These, she says, "don't cease to exist simply because we are temporarily unable to exercise them. A native English speaker doesn't lose her linguistic competence when she has laryngitis; an accomplished pianist doesn't forget how to play piano when her fingers are broken or when she is unconscious during surgery” (2013: 8). However, these agents would, in these circumstances, lose what Vihvelin calls narrow abilities to speak English or play piano.
} 
opportunity to $A$, and there must be nothing external that stands in one's way. Despite having what it takes to play guitar, you lack a wide ability to do so now if there's no guitar nearby, or if the only guitar is locked in a closet that can’t be opened, or if a guitar bully will tackle you should you reach for the guitar.

Evidently, agents can differ with regard to their wide abilities just by being in different circumstances. But what about narrow abilities? Vihvelin takes these to be intrinsic, possessed by an agent in virtue of that agent’s intrinsic properties. She says: "Necessarily, if two persons are intrinsic duplicates governed by the same laws, they have exactly the same narrow abilities" (2013: 13). Since 'narrow ability' is a term of art, perhaps the claim here is meant as stipulative, giving notice that any ability that doesn't meet the intrinsicness requirement won't be counted as narrow. ${ }^{6}$

\section{The Compatibility Question}

Compatibilism is the view that determinism is compossible with the existence of agents with free will. Incompatibilism is commonly taken to be simply the negation: it isn't possible that determinism is true and there exist agents with free will.

Vihvelin takes the dispute to concern not just any agents but those of a certain kind: nongodlike beings like us. Implications that determinism might or might not have for necessary and eternal beings aren't at issue. Further, she rejects the standard construal of incompatibilism. It fails to distinguish the view that free will is altogether impossible from the view that it is

\footnotetext{
${ }^{6}$ If an externalist theory of content is correct, then abilities (actively) to think certain thoughts might fail to count as narrow abilities, for there might be intrinsic duplicates who differ with respect to these abilities because they differ with respect to historical or other relational properties. (Thomas Reed brought this point to my attention.) Further, as Al Mele pointed out, the same might apply to abilities intentionally to perform overt actions, since intentionally Aing plausibly requires having some thought of $A$-ing.
} 
possible but not compossible with determinism. The former she calls Impossibilism. It is the latter that she takes to be Incompatibilism. As she sees it, then, Incompatibilists agree with Compatibilists that free will is possible; their disagreement is over whether this possible thing is compossible with determinism. Her defense of Compatibilism consists of mostly separate responses to these two parties, the Impossibilists and the Incompatibilists.

A minor point: the framework here leaves at least one interested party out of the picture. One might be—-some folks are—agnostic about whether free will is possible. One might nevertheless have something to say about whether it's possible for free will to exist and determinism be true. If the agnostic about Impossibilism answers this question negatively, she doesn't count as an Incompatibilist in Vihvelin's terms, though she isn't an Impossibilist, either.

In any case, in light of her distinction between narrow and wide abilities, Vihvelin considers what the Incompatibilist's position should be taken to be. Beyond the affirmation of free will's possibility, the Incompatibilist's further claim might be that, necessarily, if determinism is true, then no agent ever has any ability to act, whether narrow or wide, exercised or unexercised. Alternatively, it might be that, necessarily, if determinism is true, then no agent ever has any unexercised narrow ability. Or it might be that, necessarily, if determinism is true, then no agent ever has any unexercised wide ability.

On all three alternatives, the Incompatibilist, while accepting that free will is possible, denies that determinism is compatible with agents' having wide abilities to do things they don't in fact do. Vihvelin takes it that the free will/determinism problem is the problem of whether this latter claim is correct.

Given Vihvelin's characterizations of narrow and wide abilities and the examples she gives of ways of lacking them, an Incompatibilist might be ill advised to make any of these 
claims. Determinism manifestly doesn’t preclude our having skills, competence, or know-how to do things we don't in fact do. It doesn't entail that whenever one doesn't $A$ one is sound asleep or in a coma, or that whenever we don't use our hands, our hands are broken or we suffer from general paralysis. It doesn’t imply that our behavior “is like always acting in response to compulsive desires,” (2013: 13) or that our inabilities are like those of "the drug addict or kleptomaniac” (13). If determinism deprives us of free will, there are nevertheless clear and important differences between the actions of ordinary adult human agents and these cases of incapacitation or pathology. Nor, of course, does determinism imply that whenever you're not playing a guitar, there's no guitar in your vicinity, or that should you attempt to play, someone will smash the only nearby guitar or incapacitate you. No incompatibilist should think that “determinism is like always being surrounded by invisible force fields or followed by a bodyguard ready to thwart your every attempt to oppose his wishes, or...like always waking up too late to catch the plane” (13-14).

In fact, the Incompatibilist's view might be better stated not in terms of abilities, or not solely so, but rather as something like this: necessarily, if determinism is true, then never when an agent acts is it up to her whether she does this or that. Or, if we want to put it in terms of wide abilities, the Incompatibilist might say that, necessarily, if determinism is true, then although agents might often have wide abilities to do things they don't in fact do, it's never up to them whether they exercise this or that ability.

Arguments for Incompatibilism often conclude with a denial that it's ever up to anyone whether this or that is so. Indeed, Vihvelin occasionally characterizes free will in terms of its often being up to us which open alternative we choose. ${ }^{7}$ But showing that determinism is

\footnotetext{
${ }^{7}$ For example, in characterizing what she takes to be the common-sense view of our agency, she says, "When we try to figure out what to do, from deciding what to have for lunch to the big decisions that shape our lives, we assume
} 
compatible with free will so conceived takes more than showing that it wouldn't preclude agents' often having the skills, consciousness, intact bones, and opportunities needed to do things they don't in fact do. (I'll return to this point toward the end of the paper.)

\section{Dispositions}

As Vihvelin sees things, a defense of Compatibilism against Incompatibilism doesn't require that one advance an account of free will. It suffices to rebut arguments for Incompatibilism. ${ }^{8}$ She nevertheless sets out a detailed view of narrow abilities to act.

Vihvelin's account stems from the observation that the narrow abilities of agents are in many respects similar to the intrinsic dispositions of medium-sized objects and everyday stuff, dispositions such as fragility, elasticity, and solubility. We have empirical knowledge of such dispositions, and likewise of agents' abilities. We rely on knowledge of this sort in dealing with both inanimate things and agents. The dispositions of vases and sugar, like the abilities of agents, are often relatively stable features of these things, persisting through periods when they aren't being manifested or exercised. And just as, in some sense, an object with a disposition to $M$ can $M$, so, in some sense, an agent with an ability to $A$ can $A$.

Vihvelin ventures that narrow abilities to act are "structurally like” such dispositions. She advances what she calls the Intrinsic Dispositions Thesis:

that we are choosing from some range of alternatives. And we assume that we are able to choose any of these alternatives and that it's up to us which one we choose” (2013: 60). This seems to me right, but it isn't clear that the claim that we have wide abilities to do each of various things comes to the same thing.

${ }^{8}$ She devotes a good portion of her book to responding to these, including the well-known Consequence Argument. 
To have one of the narrow abilities in virtue of which we are agents with free will

is to have some intrinsic disposition or bundle of intrinsic dispositions. (2013:

Having wide abilities to act, she says, consists of having certain intrinsic dispositions and being in surroundings that are friendly to the manifestation of those dispositions.

What, then, is it to have an intrinsic disposition? Vihvelin offers a proposal that blends features of an account from David Lewis ${ }^{9}$ and one from David Manley and Ryan Wasserman. ${ }^{10}$ From Lewis she takes the idea that "to be disposed to $\mathrm{R}$ in response to $\mathrm{S}$ is to be intrinsically well suited for causing R (given S)” (2013: 186). And she seeks to incorporate from Manley and Wasserman their “insight that being well suited for R-ing doesn’t require a surefire or deterministic disposition” (186). Her proposal is:

(LCA-PROP) $\mathrm{x}$ is disposed at time $\mathrm{t}$ to give response $\mathrm{R}$ to stimulus $\mathrm{S}$ iff, for some intrinsic property $\mathrm{B}$ that $\mathrm{x}$ has at $\mathrm{t}$, for some time $\mathrm{t}$ ' after $\mathrm{t}$, if $\mathrm{x}$ were in a test-case at $\mathrm{t}$ and stimulus $\mathrm{S}$ occurred and $\mathrm{x}$ retained property $\mathrm{B}$ until time $\mathrm{t}^{\prime}$, then in $a$ suitable proportion of these cases, $\mathrm{S}$ and x's having of B would be an X-complete cause of x's giving response . $^{11}(186)$

\footnotetext{
${ }^{9}$ Lewis's analysis is: "Something $x$ is disposed at time $t$ to give response $r$ to stimulus $s$ iff, for some intrinsic property $B$ that $x$ has at $t$, for some time $t^{\prime}$ ' after $t$, if $x$ were to undergo stimulus $s$ at time $t$ and retain property $B$ until $t$ ', $s$ and $x$ 's having of $B$ would jointly be an $x$-complete cause of $x$ 's giving response $r$ " (1997: 157).

${ }^{10}$ Manley and Wasserman's account is: " $N$ is disposed to $M$ when $C$ if and only if $N$ would $M$ in some suitable proportion of $C$-cases” (2008: 76). C-cases are all those with the actual laws of nature in which, at the start, the object has its actual intrinsic properties and in which it is subjected to one or another detailed version of the stimulus condition C (76).

${ }^{11}$ Following Manley and Wasserman more closely, we might phrase the right-hand side of LCA-PROP as follows:
} 
Before turning to explication of the proposal, note that the target of the account is a disposition ascription. As Lewis (1997: 151) observed, we should distinguish the following two questions: What is a disposition? And what is it to have a disposition? Lewis's own proposal addresses the second question and ignores important aspects of the first. Although Vihvelin often calls her proposal an analysis of (at least some) dispositions, it, too, offers an answer to the second question. Like Lewis’s view, it leaves open, among other things, at least these two options concerning the relation between the disposition in question and the property $\mathrm{B}$ : the disposition might be said to be identical with the property, or it might be said to be a secondorder property of having some property that plays the causal role that B plays. Leaving these options open, Vihvelin’s account leaves Lewis’s first question largely unanswered. ${ }^{12}$

Now to explication and some critical remarks. First, by “an x-complete cause” of x’s giving response R, Vihvelin intends what Lewis meant in using this expression: “a cause complete in so far as havings of properties intrinsic to $x$ are concerned, though perhaps omitting some events extrinsic to $x$ ” (Lewis 1997: 156).

Second, by a "test-case,” Vihvelin says she means a case that, for the disposition in question, is relevant to testing whether something has that disposition. At least one of Vihvelin's aims in adding this provision is to head off a difficulty encountered by Lewis's proposal. A vase with a disposition to break if struck might be struck—and struck in a way that ordinarily breaks

for some intrinsic property B that $\mathrm{x}$ has at $\mathrm{t}$, for some time $\mathrm{t}$ ' after $\mathrm{t}, \mathrm{S}$ and $\mathrm{x}$ 's having of B would be an $\mathrm{x}$-complete cause of $\mathrm{x}$ 's giving response $\mathrm{R}$ in a suitable proportion of test cases in which $\mathrm{S}$ occurred and $x$ retained $B$ until t'.

To have the disposition in question, Manley and Wasserman say, an object must "satisfy a suitably high proportion of a long list of conditionals involving very precise stimulus conditions” (2011: $1194 \mathrm{n}$. 7).

${ }^{12}$ Some of Vihvelin's remarks (e.g., 2013: 262, n. 32) suggest that she sees Lewis's view as committed to the second option. Lewis is, but his analysis of disposition ascription (as he notes) is not. 
things with that disposition—but it might remain intact because it has been prepared for moving day with anti-deformation packing. The stimulus occurs, the disposition is retained, but the manifestation doesn’t occur because the disposition is “masked” by the internal packing in the vase. A similar problem is raised by cases of what is called mimicking: a brick that lacks a disposition to break if struck might nevertheless break when struck if it is attached to an explosive device that is triggered by the striking. ${ }^{13}$ Test cases for a given disposition are cases in which no masks or mimics for that disposition are present. ${ }^{14}$

Since the notion of a test case for a given disposition is spelled out using the concept of that very disposition, as it stands LCA-PROP doesn’t provide a conceptual reduction; it doesn't reduce the ascription of the disposition in question. This limitation might be removed if the relevant masks and mimics can be identified without reference to the disposition for which they are masks and mimics. But the task isn’t an easy one; for at least many dispositions, there’s no end to possible masks and mimics, and they need have no more in common than that they can mask or mimic the disposition at issue. Vihvelin might take this task to be one for future work, or she might be content with having a bi-conditional that provides an equivalence but not a reduction.

LCA-PROP follows Lewis’s proposal closely enough that, like the latter, it will have us make some surprising attributions of dispositions. Consider an ordinary soft-boiled egg. It has a disposition to splatter if dropped to the floor, and LCA-PROP will say so. But LCA-PROP apparently implies also that the egg has a disposition to bounce if dropped. It has the intrinsic property of having a certain mass and being egg-shaped. Of course, if it were dropped, it would

\footnotetext{
13 The terms 'masking' and ‘mimicking' are used by Johnston (1992: 232-33) in his discussion of dispositions. ${ }^{14}$ Lewis's own response was to build the absence of masking and mimicking conditions into the stimulus of the disposition whose ascription is being analyzed.
} 
lose this property, for it would lose its shape. But what would happen if it were dropped and it retained this property? The floor would give slightly, and then the egg would bounce. The egg's being dropped and it's having the property in question would jointly be an egg-complete cause of this response. It is, to say the least, surprising to learn that soft-boiled eggs have this disposition. $^{15}$

The case isn't one in which the stimulus finkishly causes the egg to gain the disposition in question. ${ }^{16}$ The egg already has a property that, if retained, will be all that is needed, as far as the egg is concerned, to cause it to bounce if it is dropped. Nor would the dropping trigger the intervention of something (like the explosive device attached to the brick) that will lift the egg from the floor, mimicking the disposition's manifestation; the egg would bounce on its own. Thus the appeal to test cases doesn't help. (Neither will the mention of proportionality, since in plenty of cases in which the egg is dropped and retains the property in question, it will bounce.) Vihvelin’s appeal to a “suitable proportion of cases” follows Manley and Wasserman’s strategy for dealing with the following problem. An unprotected vase that is disposed to break in response to being struck might be struck—and struck with just the degree of force that typically breaks such vases; but the vase might not break, for it might on this occasion be struck at what Manley and Wasserman (2008: 69) call a “reverse Achilles heel,” a spot such that, should the

\footnotetext{
${ }^{15}$ The example is from Yablo (2002: 133). I owe to Bird (ms) the reference to Yablo’s paper.

${ }^{16}$ Cases in which a stimulus for a given disposition causes the disposition to go away so quickly that it isn't manifested, or in which the stimulus causes an object lacking that disposition to gain it quickly enough that, given the stimulus, the disposition is manifested, are, following Martin (1994) and Lewis (1997), called (respectively) cases of finkish dispositions and cases of finkish lacks of dispositions. Lewis's analysis is meant to handle both types of case.

Although the egg doesn't finkishly lack the disposition to bounce in response to being dropped, one who accepts that the egg has this disposition might say that the disposition is finkish: it would go away if the egg were dropped, and go away quickly enough that it wouldn't be manifested. What would make the disposition finkish is some feature of the egg, for some feature of the egg would combine with the dropping to alter the egg's shape. Thus, the fink would be something intrinsic to the egg. But Lewis (1997: 157) accepted that there can be dispositions subject to intrinsic finks.
} 
vase be struck there, it would remain intact, despite its fragility. Still, Manley and Wasserman

say, if the vase breaks in a suitable proportion of the relevant possible cases in which it is struck, it counts as having a disposition to break in response to being struck.

The strategy encounters a difficulty. There might be non-denumerably many relevant possible test cases in which the vase is struck and breaks and non-denumerably many in which it is struck and doesn't break. If this is so, how are we to get a measure of proportionality on the outcomes? Manley and Wasserman (2008: 79-82) suggest several possible responses; Vihvelin does not address the problem. ${ }^{17}$

Having taken on this difficulty, Vihvelin might avoid others by jettisoning the appeal to test cases as well as the features she borrows from Lewis. Possible cases involving finks, masks, and mimics will generally be swamped by possible stimulus cases lacking these factors. There will generally be no need for further devices to deal with them. ${ }^{18}$

One final point about LCA-PROP: as I noted, its analysandum is the ascription of a disposition, in which reference to the disposition takes the form, the disposition to give response R to stimulus S. On the basis of her Intrinsic Dispositions Thesis, Vihvelin will proceed to offer an analysis, following LCA-PROP's pattern, of ascriptions of certain narrow abilities to act. But recall that what motivated the Intrinsic Dispositions Thesis was the observation that narrow

\footnotetext{
${ }^{17}$ There is a further problem that Manley and Wasserman discuss that Vihvelin does not. A fragile vase might well break if struck by an ordinary rock. It would surely break if stuck with a $10 \mathrm{~km}$-wide meteorite. But then so would many things that aren't fragile. Presumably, cases of the latter sort count less than do cases of the former sort when it comes to the disposition to break when struck. What the account needs to invoke, Manley and Wasserman say, is a weighted proportion of cases, in which some count more than others. (See their discussion at 2008: 78-79.)

${ }^{18}$ Cases of intrinsic finks, if such a thing is possible, would, however, still present a problem. Consider Johnston's (1992: 231) shy and intuitive green chameleon. Always correctly anticipating when it will be observed, it blushes and appears red on such occasions. Johnston judges that, being green, the chameleon has a disposition to appear green when observed, albeit one that is finkish: its removal is caused by its own stimulus condition. The finkishness here is due to an intrinsic feature of the chameleon, one that will tend to figure in C-cases, if these are understood the way Manley and Wasserman (2008: 76) describe them. As stated, then, their view implies that the chameleon lacks the disposition in question. Wasserman (correspondence) indicates that he would alter the specification of Ccases to accommodate cases of this sort. It is not entirely clear to me how the revision might go.
} 
abilities to act resemble in important respects dispositions such as fragility, elasticity, and solubility. We might wonder, then, what the connection is between these dispositions and LCAPROP.

The obvious reply would seem to be that a dispositional concept such as that of fragility is the concept of a disposition to give a certain type of response to a certain type of stimulus. Once we specify the relevant response and stimulus, an ascription of fragility can take the form of the analysandum in LCA-PROP.

This is in fact the strategy that Lewis suggested with respect to his own proposal. But it faces a problem. Many common disposition terms in ordinary English don’t lend themselves readily to this approach. Fragility, for example, can be manifested in many ways, including cracking, shattering, and crumbling. (A delicate instrument might simply stop working.) And the things that can stimulate a manifestation of fragility are many and varied: being compressed, being struck, or being shaken, to name a few. There is no easy way of listing all of either the possible manifestations or the possible stimuli. Nor is it clear how, even if we could list them all, they might be combined to yield an ascription that can serve as the analysandum of LCAPROP. ${ }^{19}$

There's a very different view of dispositions that evades this problem. It takes dispositions as each directed at vastly many manifestations, each of which the disposition tends to bring about with various disposition partners, different partners for different manifestations. ${ }^{20}$ On this view, there is no route from an ascription of fragility to anything like the left-hand side

\footnotetext{
${ }^{19}$ Vetter (2013) raises a similar point (though confined to stimulus conditions) with respect to efforts to analyze a disposition ascription in terms of a single conditional.

${ }^{20}$ Martin (2008) advances this kind of view.
} 
of LCA-PROP. But then, proponents of this view of dispositions don't take their ascriptions to be analyzable.

The issue here might present more of a problem for Vihvelin's treatment of dispositions than it does for her treatment of abilities to act. For in the latter case, it doesn't seem that the free-will debate concerns things on a par with fragility but instead abilities to do rather specific things - decide to accept that invitation, express a certain thought in Spanish, or drive to the supermarket and purchase a half gallon of milk. ${ }^{21}$ The abilities come with specified manifestations, at least. Hence, ascriptions of abilities might be more amenable to Vihvelin's approach than are ascriptions of dispositions such as fragility.

\section{Trying}

If for a narrow ability to act we can specify the relevant manifestation, can we likewise specify the relevant stimulus? If we can't, then we can’t offer an account of its ascription that follows the lines of LCA-PROP.

Vihvelin doesn't claim that we can do this across the board. However, she ventures that “for a highly interesting subset of our narrow abilities, to have the narrow ability to do $\mathrm{X}$ is to have an intrinsic disposition to do X in response to the stimulus of one's trying to do X” (2013: 175). She offers the following account of ascriptions of these abilities:

\footnotetext{
${ }^{21}$ Vihvelin sometimes suggests that her target includes the ability to make choices for reasons. But typically what is at issue with the compatibility question is something more specific - the ability to choose to $A$ when one hasn't in fact chosen to A. Similarly, she sometimes (e.g., 2013: 196) says that one's ability to choose on the basis of reasons, like the disposition of malleability, can be manifested in this way or in that way (in choosing to $A$ or in choosing not to $A$ [in bending this way or in bending that way]). But, again, what is usually at issue is not a generic ability to make choices but an ability to choose some specific type of action.
} 
LCA-PROP-Ability: $\mathrm{S}$ has the narrow ability at time $\mathrm{t}$ to do $\mathrm{R}$ in response to the stimulus of S's trying to do $\mathrm{R}$ iff, for some intrinsic property B that S has at t, and for some time t' after $\mathrm{t}$, if $\mathrm{S}$ were in a test-case at $\mathrm{t}$ and $\mathrm{S}$ tried to do $\mathrm{R}$ and $\mathrm{S}$ retained property B until time t', then in a suitable proportion of these cases, S's trying to do R and S's having of B would be an S-complete cause of S's doing R.

I'll focus here on the role of trying in this account. In the next section, I'll turn to some other aspects of the proposal.

Philosophers of action hold a variety of views about what trying to act is. Some take it to be a distinctly mental action, volition, that is "the ultimate core" (Ginet 1990: 73) of each overt, bodily action. On this view, when one's attempt to raise one's arm succeeds, one's act of raising one's arm is composed of one's trying to raise one's arm plus the motion of the arm that one's trying causes. Others (e.g., Adams and Mele [1992]) hold that in the case of a successful attempt to $A$, one's trying to $A$ is one's $A$-ing. When one's attempt falls short, the trying is what one does in one's failed attempt.

On neither of these views is trying related to overt action in the way that a disposition's stimulus is related to its manifestation. For on neither of these views is it the case that when one succeeds in an attempt to raise one’s arm, one’s trying to raise one’s arm causes one’s raising one's arm. On the first view, the trying partly composes the raising; on the second, it is the entirety of that action.

Vihvelin offers a different view of trying, one that is better suited to her purpose. She says, "We try to do X whenever we acquire an intention or desire to do X, here and now, and that 
intention or desire causes at least the beginning of the process of doing something that we believe, perhaps mistakenly, will move us closer towards our goal of doing X” (2013: 176). She subsequently says that, in such a case, the intention or the desire "counts as a trying” (177), and that "tryings are real events, or sequences of events" (177).

An implication of the view, apparently, is that an instance of trying counts as such due, in part, to some extrinsic feature of the trying, namely, its causing a certain thing. Two desires that are intrinsically just alike might differ with respect to whether they are instances of trying. This view of trying shares something with a causal theory of action on which an event counts as an action, when it does, because of its causal relations. But whereas the causal theory of action takes the relevant extrinsic feature to be causal ancestry, Vihvelin's view of trying takes it to be causal progeny.

Note as well that on this view trying need not be acting; an instance of trying needn't be an action. Intentions and desires are states, not actions. Even if we take Vihvelin to mean that it is coming to have an intention or desire, and not the state of intention or desire, that counts as trying, still many instances aren’t actions, for the acquisition of a desire, though an event, isn't an action. True, apparently on Vihvelin's view one tries only if one at least begins to perform some action; an intention or desire without such an effect doesn't count as an instance of trying. Still, the thing that counts as the trying precedes the beginning of the action it causes and needn't itself be an action of any sort.

This last feature puts Vihvelin's notion of trying in conflict with an ordinary notion of this phenomenon. But I think we can take Vihvelin to be introducing a technical notion designed to play a certain role in her account of narrow ability. If we prefer, we might replace 'trying' in LCA-PROP-Ability with 'intending or desiring (or coming to intend or desire) to do something 
straightaway, provided that it has a certain causal effect', where the effectiveness is spelled out as Vihvelin suggests. We shouldn't get hung up on the word here, but neither should we mistake what Vihvelin is talking about with what we ordinarily think of as trying.

We might, however, wonder why she doesn't simply take the stimuli for narrow abilities to be intentions or desires to act straightaway, or acquisitions of these, without the requirement that the state or event in question have the indicated causal effect. Perhaps the thought is that the power to move from having (or coming to have) an intention to act straightaway, or a desire to do so, to beginning to implement that state in action is an important component of an agent's ability to act. However, on Vihvelin's view, the power to make that transition is obscured, wrapped up in an extrinsic requirement for an intention or desire (or acquisition thereof) to count as trying.

Vihvelin takes up the question whether, in order to have a narrow ability to $A$, one must have a narrow ability to try to $A$. She imagines that it might be said that an affirmative answer would generate a vicious regress while a negative answer would imply that "our narrow abilities to act are mere dispositions, and we have no more control over their exercise - that is, over our actions — than natural objects have over the manifestation of their dispositions” (2013: 175).

Vihvelin answers in the negative, initially offering the following argument. Having a disposition to give response $R$ to stimulus $S$ doesn't require having any additional disposition to undergo stimulus $S$ in response to any further stimulus $S$ '. And since to have a narrow ability to $A$ is to have a disposition to $A$ in response to trying to $A$, having this ability doesn't require having any further disposition to undergo the stimulus of trying to $A$ in response to any further stimulus (2013: 176). 
There is different reply that I would have expected here. Vihvelin doesn't in fact hold that for every narrow ability to $A$, to have that ability is to have a disposition to $A$ in response to trying to A. I'll later point out a reason why she should in fact reject this universal claim. For some narrow abilities to do certain things, the relevant stimuli might be tryings, but not tryings to do those things. ${ }^{22}$ There is then no apparent reason to think that abilities to try to do those things are needed in order to have those narrow abilities. As the question is stated, the negative answer is surely right.

What about the claim that Vihvelin makes regarding dispositions? Might a vase have a disposition to break in response to being struck and yet have no disposition to be struck in response to anything whatsoever? Note that the stimulus for this second disposition needn't be at all likely to occur; indeed, things can have dispositions whose stimuli never occur. Nor is it clear that a vase protected by a vigilant rock catcher lacks a second disposition to be struck in response to something — having a rock thrown at it when the catcher sleeps (even if this is something that never in fact happens) might be something that would result in its being struck.

But suppose that Vihvelin's claim about dispositions is correct: something can have a disposition to $R$ in response to $S$ but not have any disposition to undergo $S$ in response to any stimulus $S^{\prime}$. What does that tell us about narrow abilities to act? It might show us that they—or at least some of them-have an interesting feature that distinguishes them from, for example, a disposition to break if struck.

Imagine a medieval knight who is as clever and agile as his fellows. Suppose that he isn't asleep or paralyzed. Still, I'd imagine, he isn't able to look around for an iPhone. It isn’t the lack

\footnotetext{
${ }^{22}$ Vihvelin says at one point: "I never claimed that every ability to act is a disposition that has as a stimulus condition the person's trying” (2013: 180). But her point here is different from the one I make in the text. My point concerns what one is trying when one tries.
} 
of an iPhone in his vicinity that precludes his having this ability. That lack might preclude his having the wide ability to find an iPhone. But it has no bearing on the narrow ability to look around for one.

If the knight lacks this ability, what seems to preclude his having it is his having no idea what an iPhone is. He can't think of one, he has no idea what he'd be looking for in looking for one. Consequently he can't desire or intend to do so. And, in the case of looking for some kind of thing, it does seem that having a desire or intention to look for a thing of that kind is needed if one is to look for one.

The example suggests that, at least in the case of some actions of $A$-ing, to have a narrow ability to $A$, one must have a power to try to $A$. This seems particularly so given Vihvelin's view of trying as a kind of intending or desiring (or coming to so intend or desire). If it isn't true regarding dispositions generally that in order to have a disposition to $R$ in response to $S$ an object must have a disposition to undergo $S$, then it appears that at least some narrow abilities to act are exceptional in this respect.

A second consideration seems to reinforce this suggestion. Again, let's restrict attention to actions of $A$-ing that cannot be performed without desiring or intending to $A$. (I've just given one example of such an action.) Suppose that, for some action $A$ of this type, John can come to intend or desire to A straightaway, but he can't begin to implement either of these states. Unless their implementation begins, they don’t count, on Vihvelin’s view, as instances of trying. John, then, can't try to $A$. How, we might wonder, can he nevertheless have a narrow ability to $A$ ?

Even in the case of actions of $A$-ing that can be performed-and perhaps performed intentionally_-without desiring or intending to $A$, there is often some range of desires or intentions one or another of which one must have in order to A. If one can’t come to have any 
such desire or intention, or if one can come to have them but can't even begin to implement them, it seems questionable whether one has what it takes to $A$, that one has what Vihvelin calls a narrow ability to $A$.

As we'll see in the next section, Vihvelin thinks that there are indeed cases in which an agent is unable to try to $A$ but has a narrow ability to $A$. But I'll observe then, and I note here, that if trying to do one thing or another is necessary for A-ing, and if an agent can't try to do any of the requisite things, it hardly seems that it is up to that agent whether she A-s. If we want an account that captures not just the idea that we have narrow and wide abilities to do various things, but also the idea that often it's up to us whether we do this or that, a requirement of a power to try can’t be easily rejected.

If any abilities to act are dispositions, they might come only in certain packages. Having an ability to $A$ apparently requires having certain powers to acquire beliefs, desires, and intentions, and beliefs, desires, and intentions with certain contents, even if it doesn't require having an ability to try to $A .^{23}$

Given Vihvelin's view of trying, there’s a further reason why there’s no regress of abilities to act. A disposition to try, on her view, is a disposition to come to have an intention or desire to act straightaway, one that has a certain relational property. The manifestation of this disposition would be the acquisition of the intention or desire. The manifestation might be an action in some cases, when one comes to have an intention to $A$ by making a decision to $A$. But it will often not be an action of any type. The manifestation might be one's coming to have a

\footnotetext{
${ }^{23}$ If we want some package of dispositions to suffice, as far as the having of dispositions is concerned, for having free will, we might do well to include among them dispositions to treat certain facts as reasons when and for what they are, and dispositions to become appropriately motivated upon recognizing reasons. An agent who can't become motivated to $A$ when presented with good reason to $A$ isn't the best candidate for someone who is free with respect to A-ing. See Clarke and Reed (2015: 18-20) for discussion of this point.
} 
desire, or one's coming to have an intention without having made any decision. (Think of the intention to open your office door straightaway, something that you routinely come to have, without making a decision, when you arrive at your office.) When the manifestation of the disposition to try isn’t an action, the disposition isn’t an ability to act. There’s no regress of abilities to act here, even if having a narrow ability to A requires that one have a variety of dispositions.

As I mentioned, Vihvelin doesn't claim that LCA-PROP-Ability covers every narrow ability to act. It is worth noting that it leaves out abilities that are commonly thought to be central to free will—abilities to decide this or that. Ordinarily, when one decides to A, one doesn't first intend to decide to $A$, or desire to decide to $A$, and one's decision to $A$ isn't caused by such an intention or desire. Thus, an ordinary ability to decide to $A$ isn't a disposition to decide to $A$ in response to the stimulus of trying to decide to $A$.

Sometimes a decision to $A$ is preceded by an intention to make up one’s mind here and now whether to $A$. Provided that so intending has the required effect, it may count, on Vihvelin's view, as trying to make up one's mind whether to A. Perhaps one kind of narrow ability to decide to $A$ might then be construed as a disposition to do so in response to a stimulus of this sort. ${ }^{24}$ However, this strategy does not appear to give us a general account of a narrow ability to decide to $A$, since, it appears, one can make such a decision without first having the indicated here-andnow intention. ${ }^{25}$

\footnotetext{
${ }^{24}$ There is, however, the following peculiarity. If, as is sometimes said (e.g., by Mele [2000]), deciding is a momentary mental action, it is hard to see what might count as a "beginning of the process" of deciding. Then intending to make up one's mind would seem to count as trying only in cases of success; there can be no trying and failing in such a case.

${ }^{25}$ Thanks to Al Mele for emphasizing this point. As he noted, sometimes what one intends is to make up one's mind (full stop), and not to make up one's mind right now, and such an intention might be acquired well before the resulting decision is made. An intention of this sort, whatever its causal efficacy, will not count as an instance of trying, on Vihvelin's view.
} 


\section{Narrow Abilities}

I turn now to further examination of LCA-PROP-Ability. Patterned as it is after LCA-PROP, it inherits features of that account of disposition ascriptions.

For one, without further explication of what a test case is, LCA-PROP-Ability isn't a reductive analysis. Vihvelin says that a test case for a given narrow ability to act is a case suited for testing whether an agent has that ability. For example, a test case for a narrow ability to ride a bicycle is one in which the agent is

in surroundings where the extrinsic enablers (e.g., a bicycle and a place to ride it) for the ability are in place and where there are no extrinsic masks (e.g., bicycle bullies lurking in the background) to the exercise of the ability.... (2013: 187) $)^{26}$

The familiar notion of an opportunity might serve to convey what is expressed here in terms of enablers. But as things stand, we seem reliant on the concept of the ability in question in order to specify the absence of masks (and mimics). Perhaps there's some way to indicate them without using that concept, but Vihvelin hasn't shown what it might be.

LCA-PROP-Ability inherits from Manley and Wasserman’s proposal the difficulty concerning a measure of proportions when there are infinitely many test cases with each of two or more outcomes. And given what LCA-PROP-Ability incorporates from Lewis's analysis of dispositions, it seems to yield some peculiar verdicts about agents’ abilities. Consider:

\footnotetext{
${ }^{26}$ Vihvelin adds: "and where the person retains the intrinsic property B that is the causal basis of the ability." But the addition isn't needed in spelling out what a test case is, since a distinct clause of the analysans secures this condition.
} 
Ordinarily Sam can raise his right arm as well as any of us. Not so today. A key nerve bundle leading from his brain to his shoulder, though connected, is loose. Were Sam to try to raise his right arm, the nerves would disconnect, and he would fail to move his arm.

Sam has ordinary strength, and the key nerves are currently connected. Thus, he has an intrinsic property such that, were he to try to raise his right arm and retain that property for some time, his trying and his having that property would jointly be a Sam-complete cause of his act of raising his arm. We may further suppose that most cases in which he tried and retained that property would yield this result. LCA-PROP-Ability apparently implies, then, that Sam has the narrow ability to raise his right arm in response to trying to raise the arm. That is an unwelcome result.

Again, the case isn’t one of a finkish lack of the disposition in question. The stimulus wouldn't cause Sam to gain a causal basis of the ability; he already has such a basis. Nor is the case one of mimicking; it isn't that the stimulus would cause someone else to lift Sam's arm. Perhaps something further about test cases blocks the apparent implication, but it would have to be explained what that is.

Bullet-biting would not be an entirely satisfactory move here. Even if there is a kind of ability to raise his right arm that Sam has, it isn’t currently up to him whether he raises the arm. (And the problem isn't with his surroundings; they're perfect friendly to right-arm-raisings.) If we want an account that captures the idea that it's often up to us 
whether we do this or that, it had better deny that Sam has the kind of ability that it concerns.

I don't see that Vihvelin takes up a case of this kind. She does respond to several standard objections to older conditional analyses of (ascriptions of) abilities to act, arguing that each either failed in the first place or, though holding against one or another older analysis, fails against LCA-PROP-Ability. I find much of what Vihvelin says here convincing. Her discussion of Chisholm's objection is an exception.

Chisholm considered the proposal that 'he could have done otherwise' means the same thing as 'if he had chosen to do otherwise, then he would have done otherwise'. (Instead of 'chosen’, Chisholm noted, one might say 'tried’.) Against the claimed equivalence, he objected that in some case it might be true of some agent that if he had chosen to do otherwise, then he would have done otherwise, but also true that he couldn't have chosen to do otherwise. In that case, Chisholm claimed, the agent couldn’t have done otherwise (2003: 28-29).

Chisholm apparently held that, as a general matter, if one couldn’t have chosen otherwise, then one couldn't have done otherwise. But one sometimes A-s without first choosing to $A$, and one might be able to $A$ without first so choosing. Having an ability to choose to $A$ isn't a strict requirement for having an ability to $A$.

Still, we might wonder, mightn't there be cases in which an agent can’t A because she can't choose to A, even though it's true that were she to choose to $A$ she would A? Chisholm offered no argument that there might be, and he presented no example illustrating the possibility. Many have taken an example from Keith Lehrer to fit the bill. Here is Lehrer's example: 
Suppose that I am offered a bowl of candy and in the bowl are small round red sugar balls. I do not choose to take one of the red sugar balls because I have a pathological aversion to such candy. (Perhaps they remind me of drops of blood and....) It is logically consistent to suppose that if I had chosen to take the red sugar ball, I would have taken one, but not so choosing, I am utterly unable to touch one. (1982: 44)

Vihvelin objects that, on a natural way of understanding the case, the agent is able to take a red candy. "We should say that the person lacks one narrow ability — the ability to choose, on the basis of reasons, to take the candy...-while retaining another narrow ability - the ability to take the candy... as the upshot of choosing to do so” (2013: 203). The agent here has a disability of will; his will is paralyzed. But there is no reason, she says, to think he has a disability of body, that his body is paralyzed as well.

Of course, bodily paralysis isn’t required for the agent to lack a narrow ability to take a candy. Recall that one thing required for narrow ability is the psychological capacity to exercise one’s know-how. And we might think that the agent in this case lacks that.

In any event, there are other cases that seem to illustrate the possibility in question, or something equally troubling for LCA-PROP-Ability. Consider in this light the medieval knight. He can’t try to look for an iPhone. And he can’t look for an iPhone, apparently because he lacks what it takes to try to look for one. But it might well be that he'd look for an iPhone if he tried to look for one. And I see no reason to think that the right-hand side of LCA-PROP-Ability isn't satisfied with respect to his ability to look for an iPhone. It seems that lacking what it takes to try is all that stands in his way. 
The same goes for an agent who, although she can acquire the requisite desires and intentions, can't begin to implement any desire or intention that might motivate $A$-ing. She lacks what it takes to try to A. And lacking this, it seems that she isn't able to A. It might still be the case that she'd $A$ if she tried to do one or another of the relevant things. And it might be that the right-hand side of LCA-PROP-Ability is satisfied with respect to this agent and her ability to A.

Whatever we say about the narrow abilities of these agents, this much seems clear: if they can't try to do anything such that their so trying might result in their doing the thing in question, then it hardly seems up to them whether they do that thing.

A similar observation applies to the agent in Lehrer's case. If we suppose that he can't take a red candy without choosing to do so, then it isn't up to him whether he takes a red candy. If he nevertheless has a narrow ability to take a red candy in response to so choosing, then, given that he'd then also have the wide ability to do so, what we see is that having both narrow and wide abilities to do certain things doesn't suffice for its being up to us whether we do them.

\section{Up to You}

Vihvelin's main defense of Compatibilism is her response to various arguments for Incompatibilism. But she offers a second, independent argument based on her account of abilities to act. Narrow abilities are dispositions, or bundles of these. Since determinism gives us no reason to deny that things have unmanifested dispositions, it gives us no reason to deny that we have unexercised narrow abilities. It likewise gives us no reason to deny that we also have unexercised wide abilities to act (no reason to think that, for example, whenever you don't drive to the store and get milk, either your car isn’t working or the store is closed). Therefore, determinism gives us no reason to think that we lack free will (2013: 169-70). 
The argument would benefit from the further premise that it suffices for our having free will that we have a sufficiently rich package of narrow and wide abilities, including many abilities to do things we don't in fact do. Vihvelin asserts that this is so. She says, "We have the free will we think we have by having some relevant bundle of dispositions and by being in surroundings that are suitably friendly with respect to the manifestation of these dispositions” (2013: 169). But further argument is needed to support this claim.

As I noted earlier, Vihvelin sometimes characterizes free will in terms of its (sometimes) being up to us whether we do this or that. I think she's right to do so. Granted, there are uses of 'up to you' that express ideas that aren’t particularly concerned with free will. The phrase can be used to indicate that what happens subsequent to your decision depends on what you decide. Or it can be used to indicate that no one will tell you what to do or exert any pressure on you to do this or that. But some first-personal employment of the phrase in thought is, I think, rather different. Commonly when one is deliberating about whether to $A$, one presumes that it's up to oneself whether one decides to $A$. One presumes not just that one’s decision will be a differencemaker with regard to what happens subsequent to it, but that it's up to oneself whether one makes this decision or that. And one might presume this even if one knows that someone else is advising or pressing one to decide a certain way.

The thought expressed in such a case is part of our ordinary idea of our freedom. Any account of free will that aims to capture that ordinary idea must capture this thought. I think that Vihvelin agrees.

However, if this is indeed her goal, then the argument summarized at the start of this section falls short. An agent with an interesting bundle of dispositions and in friendly surroundings might have a rich array of narrow and wide abilities to do things that she doesn't in 
fact do. If an agent might have such abilities even if determinism is true, this is an important fact. But it will take further argument to show that having such dispositions and being in such surroundings suffices for its being up to you, on some occasions, whether one or another of these dispositions is manifested, and hence whether you do this or that.

If determinism is true, then whether a disposition to give response $R$ to stimulus $S$ is manifested on some occasion is a matter of whether antecedents sufficient for that manifestation have occurred. When a vase that is disposed to break if struck is struck, it breaks_-or it doesn't—-depending on how it's struck, how fragile it is, and perhaps other features of the vase and the situation. Plainly it isn’t up to the vase whether it breaks. Adding indeterminism to the picture changes nothing in this respect; whether the disposition is manifested on some occasion might now be a matter of whether certain antecedents occur and of chance, but it's no more up to the vase.

Of course, the dispositions that Vihvelin takes to be our narrow abilities to act differ in interesting and important ways from the vase’s fragility: their stimuli are events internal to us, psychological events such as coming to have a certain intention; and their manifestations are our actions. Further, an adult human agent commonly has a rich package of associated abilities "to conjure up and contemplate alternative ways of acting, to weigh ends, to deliberate for the purpose of deciding what to do, to make plans for the future, to examine and criticize her past actions and current motives, to make resolutions to act differently in the future” (2013: 179). As Vihvelin puts it, "we have control over what we do not because we have dispositions but because we have the kinds of dispositions distinctive of creatures with minds and the ability to move their minds and bodies in goal-directed and other intelligent ways” (178). 
Still, if all of these abilities are structurally similar to the fragility of the vase, the question remains: how is it ever the case that whether one or another of them is manifested on some occasion isn't simply a matter of whether certain antecedents have occurred, and perhaps of chance? How is it that it is ever up to oneself whether one or another of these dispositions is manifested?

The problem here isn't one presented by determinism; hence no response to the Consequence Argument, or to similar arguments for Incompatibilism, addresses it. The issue is whether any dispositional account of abilities can capture the idea of its sometimes being up to us whether we do this or that. ${ }^{27}$ Despite its sophistication, I do not think that Vihvelin's view of abilities to act has shown that an account of this sort can achieve this goal. ${ }^{28}$

\footnotetext{
${ }^{27}$ Clarke and Reed (2015: 26-28) discuss this question and offer a brief suggestion concerning how an affirmative answer might go.

${ }^{28}$ A version of this paper was presented at a symposium on Vihvelin's book at the University of Southern

California, September 2014. I'm grateful to Kadri Vihvelin and to the audience on that occasion for their responses.
} 


\section{References}

Adams, Frederick and Alfred R. Mele. 1992. “The Intention/Volition Debate.” Canadian Journal of Philosophy 22: 323-37.

Austin, J. L. 1979. “Ifs and Cans.” In Philosophical Papers, $3^{\text {rd }}$ edition, ed. J. O. Urmson and G. J. Warnock, 205-32. Oxford: Clarendon Press.

Berofsky, Bernard. 2011. “Compatibilism without Frankfurt: Dispositional Analyses of Free Will.” In The Oxford Handbook of Free Will, 2nd edition, ed. Robert Kane, 153-74. New York: Oxford University Press.

Bird, Alexander. Ms. “Can Dispositions Have Intrinsic Interferers?”

Campbell, Joseph Keim. 2011. Free Will. Cambridge: Polity Press.

Chisholm, Roderick M. 2003. “Human Freedom and the Self.” In Free Will, $2^{\text {nd }}$ edition, ed. Gary Watson, 26-37. Oxford: Oxford University Press.

Clarke, Randolph and Thomas Reed. 2015. “Free Will and Agential Powers.” In Oxford Studies in Agency and Responsibility, vol. 3, ed. David Shoemaker, 6-33. Oxford: Oxford University Press.

Ginet, Carl. 1990. On Action. Cambridge: Cambridge University Press.

Johnston, Mark. 1992. “How to Speak of the Colors.” Philosophical Studies 68: 221-63.

Lehrer, Keith. 1982. “Cans without Ifs.” In Free Will, $1^{\text {st }}$ edition, ed. Gary Watson, 41-45. Oxford: Oxford University Press.

Lewis, David. 1997. “Finkish Dispositions.” Philosophical Quarterly 47: 143-58.

Maier, John. 2014. “Abilities.” Stanford Encyclopedia of Philosophy, http://plato.stanford.edu/entries/abilities/

Manley, David and Ryan Wasserman. 2008. “On Linking Dispositions and Conditionals.” Mind 
117: 59-84.

------. 2011. “Dispositions, Conditionals, and Counterexamples.” Mind 120: 1191-227. Martin, C. B. 1994. “Dispositions and Conditionals.” Philosophical Quarterly 44: 1-8. ------. 2008. The Mind in Nature. Oxford: Clarendon Press.

Mele, Alfred R. 2000. “Deciding to Act.” Philosophical Studies 100: 81-108.

------. 2006. Free Will and Luck. New York: Oxford University Press.

Steward, Helen. 2012. A Metaphysics for Freedom. Oxford: Oxford University Press.

Vetter, Barbara. 2013. “Multi-Track Dispositions.” Philosophical Quarterly 63: 330-52.

Vihvelin, Kadri. 2013. Causes, Laws, and Free Will: Why Determinism Doesn't Matter. New York: Oxford University Press.

Yablo, Stephen. 2002. “De Facto Dependence.” Journal of Philosophy 99: 130-48. 